\title{
ĐÁNH GIÁ KẾT QUẢ TRUNG HẠN ĐIỀU TRI PHİNH ĐỘNG MẠCH CHỦ BỤNG DƯớI THẬN BẦNG CAN THIỆP NỘI MẠCH
}

\section{TÓM TẮT}

Muc tiêu: Nghiên cứu này được thực hiện nhằm đánh giá kết quả trung hạn ứng dụng kỹ thuật can thiệp đặt ống ghép nội mạch điều trị phình động mạch chủ bụng dưới thận.

\section{Đối tượng và phương pháp nghiên cúu:} Nghiên cứu mô tả dọc tiến cứu. Đối tượng là bệnh nhân phình động mạch chủ bụng dưới thận có kèm hoặc không kèm theo phình động mạch chậu tại khoa Phẫu thuật Mạch máu Bệnh viện Chợ Rẫy, trong thời gian từ tháng $5 / 2012$ đến tháng $8 / 2017$ được điều trị bằng can thiệp nội mạch.

Kết quả: Có tất cả 95 trường hợp (71 nam và 24 nữ) đủ tiêu chuẩn đưa vào nghiên cứu. Tuổi trung bình là 73,8 $\pm 17,6$ tuổi. Thời gian theo dõi trung bình là $33 \pm 19$ tháng. Tỷ lệ rò nội mạch muộn là $6,3 \%$. Không có trường hợp nào di lệch ống ghép, 6 trường hợp cần can thiệp lại. Tỷ lệ tử vong trung hạn là $21,1 \%$ trong đó có 2 trường hợp $(2,1 \%)$ tử vong liên quan đến túi phình.

Kết luận: Tỷ lệ tử vong trung hạn và tỷ lệ can thiệp lại trung hạn của can thiệp nội mạch động mạch chủ đều ở mức ngang bằng hoặc cao hơn so với phẫu thuật mở. Như vậy, can thiệp nội mạch động mạch chủ rất có lợi trên những bệnh nhân lớn tuổi, nhiều bệnh kèm và yếu tố nguy cơ.

Tù khóa: phình động mạch chủ bụng dưới thận, điều trị nội mạch phình ĐMCB, ống ghép nội mạch
Nguyễn Văn Quảng*, Trần Quyết Tiến ${ }^{* *}$

\section{MIDTERM OUTCOMES OF \\ ENDOVASCULAR REPAIR FOR \\ INFRARENAL ABDOMINAL AORTIC ANEURYSMS}

\section{ABSTRACT}

Objective: This study was performed to evaluate the mid-term outcomes of endovascular aneurysm repair (EVAR) in the treatment of infrarenal abdominal aortic aneurysms (AAA).

Materials and method: This is a prospective study. All cases of infrarenal AAA were treated by EVAR at Vascular surgery Department, Cho Ray Hospital from May-2012 to August-2017.

Results: A total of 95 cases (71 males and 24 females) were eligible for inclusion in the study. The mean age was $73,8 \pm 17,6$. The mean follow-up time was $33 \pm 19$ months. The rate of late endoleak was $6,3 \%$. There was no case of graft migration and 6 cases requiring re-intervention. The mid-term mortality rate was $21.1 \%$ of which 2 cases $(2.1 \%)$ were related to aneurysms.

Conclusion: The mid-term mortality rates and re-intervention rates of EVAR were both equal or higher than that of conventional surgery. Thus, EVAR is very beneficial in elderly patients associated with comorbidities and risk factors.

Key words: Abdominal Artery Aneurysm (AAA), EVAR, Stent graft

\footnotetext{
* Khoa phẫu thuật mạch máu, Bệnh viện Chọ Rẫy

** Bộ môn Phẫu thuật Lồng ngực Tim mạch, Đại học Y Dựcc Thành phố Hồ Chí Minh

Nguoòi chịu trách nhiệm khoa học: Nguyễn Văn Quảng

Ngày nhận bài: 31/03/2021 - Ngày cho phép đăng: 27/04/2021
} 


\section{ĐẠT VẤN ĐỀ}

Sự ra đời của phương pháp đặt ống ghép qua can thiệp nội mạch (EVAR) đã mở ra một cuộc cách mạng trong điều trị ngoại khoa phình động mạch chủ. Tính hiệu quả và an toàn của EVAR trong giai đoạn sớm đã được chứng minh qua các nghiên cứu thử nghiệm lâm sàng đơn trung tâm và đa trung tâm với thời gian nằm viện ngắn, tỷ lệ biến chứng và tử vong chu phẫu thấp [1], [2], [3]. Tuy nhiên, cần phải đánh giá kết quả trung hạn cũng như dài hạn để có cái nhìn toàn diện hơn về phương pháp này và trả lời cho câu hỏi liệu can thiệp nội mạch có thay thế hoàn toàn được phẫu thuật mở kinh điển hay không? Tại bệnh viện Chợ Rẫy, EVAR đã được ứng dụng trong điều trị phình động mạch chủ bụng từ năm 2012, tính hiệu quả và an toàn qua theo dõi ngắn hạn cũng đã được chứng minh [4], [5]. Tuy vậy, cần có một nghiên cứu theo dõi lâu hơn để đánh giá cụ thể hơn hiệu quả của phương pháp này. Nghiên cứu này được thực hiện với mục tiêu đánh giá kết quả trung hạn ứng dụng EVAR trong điều trị phình động mạch chủ bụng dưới thận tại Bệnh viện Chợ Rẫy.

\section{ĐỐI TƯợNG VÀ PHƯƠNG PHÁP NGHIÊN CÚU}

Thiết kế nghiên cứu: Mô tả dọc tiến cứu

Đối tuọng nghiên cúu:

- Tiêu chuẩn chọn bệnh: Bệnh nhân được chẩn đoán xác định phình động mạch chủ bụng dưới thận có kèm hoặc không kèm theo phình động mạch chậu tại khoa Phẫu thuật Mạch máu Bệnh viện Chợ Rẫy, trong thời gian từ tháng $5 / 2012$ đến tháng $8 / 2017$ được điều trị bằng phương pháp đặt ống ghép qua can thiệp nội mạch (EVAR).

- Tiêu chuẩn loại trừ bao gồm: (1) Các bệnh nhân có phình động mạch chủ ngực, phình động mạch thân tạng, động mạch mạc treo tràng trên kèm theo. (2) Có phẫu thuật động mạch chủ trước đó. (3) Bệnh nhân có hẹp, tắc động mạch chậu đùi hai bên kèm theo. (4) Có bệnh lý ác tính, bệnh nội khoa nặng tiên lượng sống dưới 6 tháng.

\section{Phưong pháp nghiên cúu:}

- Cỡ mẫu nghiên cứu: Số lượng bệnh nhân cần cho nghiên cứu được tính dựa vào công thức ước lượng cỡ mẫu theo một tỷ lệ bệnh trong dân số ở khoảng tin cậy 95\%. Cỡ mẫu được tính theo công thức sau:

$$
\mathrm{N}=\frac{\mathrm{Z}_{(1-\alpha / 2)}^{2} \times \mathrm{p}(1-\mathrm{p})}{\mathrm{d}^{2}}=\frac{1.96^{2} \mathrm{p}(1-\mathrm{p})}{\mathrm{d}^{2}}
$$

(Z: trị số từ phân phối chuẩn; $\alpha$ : xác suất sai lầm loại $\mathrm{I}$; $\mathrm{p}$ : trị số mong muốn của tỷ lệ; d: độ chính xác (hay là sai số cho phép); Với $\alpha=0,05$; $\mathrm{Z}_{0,975}=1,96 ; \mathrm{p}=0,90 ; \mathrm{d}=0,07 \Rightarrow \mathrm{N} \geq 71 \quad \mathrm{p}=0,90$ trị số mong muốn của tỷ lệ thành công của phương pháp can thiệp đặt ống ghép nội mạch điều trị phình động mạch chủ bụng dưới thận, tham khảo công trình nghiên cứu của tác giả Jean-Piere Becquemin [3]).

- Các mốc thời gian bệnh nhân khám lại và lưu trữ kết quả là 1 tháng, 3 tháng, 6 tháng, 12 tháng sau can thiệp và hàng năm sau đó cho đến khi kết thúc nghiên cứu. Trường hợp bệnh nhân còn sống thời gian theo dõi ngắn nhất là 12 tháng (đến tháng 08/2018).

- Thành công về mặt kỹ thuật: trong quá trình can thiệp, bung ống ghép đúng vị trí (xác định qua chụp cản quang), không lấp động mạch thận. 
- Đánh giá kết quả trung hạn (sau 30 ngày) dựa trên các tiêu chí đánh giá kết quả qua thăm khám lâm sàng và chụp MSCT động mạch chủ theo phân tích gộp các nghiên cứu: EVAR1, DREAM, OVER, ACE của tác giả Powell và cộng sự (2017) [6]:

+ Tỷ lệ biến chứng muộn, tỷ lệ tử vong chung, tử vong do tim mạch, tử vong liên quan phình

+ Tỷ lệ rò nội mạch muộn, phương pháp xử lý

+ Tỷ lệ can thiệp lại, lý do can thiệp lại.

- Phuơng pháp thống kê và phân tích số liệu: Xử lý và phân tích thống kê số liệu dựa trên phần mềm thống kê $\mathrm{R}$ 3.4.4. Các biến liên tục được mô tả dưới dạng trung bình \pm độ lệch chuẩn nếu phân phối bình thường hoặc gần bình thường, hoặc trung vị và khoảng tứ phân vị nếu phân phối lệch, biến rời rạc được trình bày dưới dạng số bệnh nhân và tỷ lệ \%. Các kết cuộc trong thời gian theo dõi (rò, tử vong) được mô tả bằng biểu đồ Kaplan-Meier.

\section{KẾT QUẢ}

Trong khoảng thời gian từ tháng 5/2012 đến tháng $8 / 2017$, có tất cả 95 bệnh nhân phình động mạch chủ bụng đủ điều kiện đưa vào nghiên cứu. Tuổi trung bình là 73,8 $\pm 17,6$, nhóm tuổi từ 71-80 tuổi chiếm tỷ lệ cao nhất $(35,8 \%)$. Nam giới chiếm $74,7 \%$ nhóm nghiên cứu. Tất cả bệnh nhân được tiến hành can thiệp đặt ống ghép nội mạch với tỷ lệ thành công về mặt kỹ thuật đạt 98,9\% . Có 1 trường hợp $(1,1 \%)$ ống ghép bung sai vị trí gây lấp bán phần động mạch thận phải. Sau can thiệp, chúng tôi theo dõi sát trường hợp này, chức năng thận giảm sau can thiệp sau đó trở về bình thường sau 1 tháng theo dõi. Thời gian theo dõi trung bình là $33 \pm 19$ tháng. Thời gian theo dõi ngắn nhất là 1 tháng và thời gian theo dõi dài nhất là 74 tháng. Các biến chứng sớm được liệt kê trong bảng 1 . Trong thời gian theo dõi trung hạn (sau 30 ngày), chúng tôi ghi nhận các biến chứng muộn của can thiệp bao gồm: Rò nội mạch muộn, di lệch ống ghép, tăng kích thước túi phình, các trường hợp can thiệp lại, tỷ lệ tử vong và nguyên nhân.

Bảng 1: Các biến chứng sớm

\begin{tabular}{|c|c|c|}
\hline Biến chứng & Số bệnh nhân (n) & Tỷ lệ (\%) \\
\hline Nhồi máu cơ tim & 1 & 1,1 \\
\hline Viêm phổi & 0 & 0 \\
\hline Suy thận cấp & 1 & 1,1 \\
\hline Lấp động mạch thận & 1 & 1,1 \\
\hline Suy đa cơ quan & 1 & 1,1 \\
\hline Nhiễm trùng vết mổ & 0 & 0 \\
\hline Tụ máu vết mổ & 11 & 11,6 \\
\hline Mổ lại cầm máu & 0 & 0 \\
\hline Tắc mạch chi sau can thiệp & 0 & 0 \\
\hline Di lệch ống ghép & 0 & 0 \\
\hline Tử vong trong vòng 30 ngày & 1 & 1,1 \\
\hline
\end{tabular}


Bảng 2: Các biến chứng trong theo dõi trung hạn

\begin{tabular}{lcc}
\hline Biến chứng & Số bệnh nhân (n) & Tỷ lệ (\%) \\
\hline Rò nội mạch & 6 & 6,3 \\
Tăng kích thước túi phình & 6 & 6,3 \\
Can thiệp lại & 6 & 6,3 \\
Tử vong trung hạn & 20 & 21,1 \\
\hline
\end{tabular}

\section{Rò nội mạch muộn}

Trong thời gian theo dõi trung hạn, có 6 trường hợp rò nội mạch, chiếm 6,3\% các bệnh nhân can thiệp động mạch chủ bụng. Chi tiết về phân loại rò nội mạch và xử trí được mô tả trong bảng 3.

Bảng 3: Rò nội mạch muộn

\begin{tabular}{clcl}
\hline STT & Thời điểm & Loại rò & Phương pháp can thiệp \\
\hline 1 & 36 tháng & IB & Từ chối can thiệp lại \\
2 & 24 tháng & IB & Từ chối can thiệp lại \\
3 & 36 tháng & IA & Chuyển mổ hở \\
4 & 15 tháng & IA & Đặt ống ghép nối thêm ở cổ túi phình \\
5 & 13 tháng & IB & Đặt ống ghép nối thêm ở động mạch chậu \\
6 & 16 tháng & II & Thả coil làm tắc động mạch thắt lưng chậu \\
\hline
\end{tabular}

\section{Di lệch ống ghép và thay đổi kích thước} túi phình

Chúng tôi ghi nhận có 6 bệnh nhân tăng kích thước túi phình $(6,3 \%), 29$ bệnh nhân giảm kích thước túi phình $(30,5 \%)$ và 60 trường hợp không thay đổi kích thước túi phình (63,2\%)

\section{Can thiệp lại}

Có 6 trường hợp cần can thiệp lại trong thời gian theo dõi, chiếm tỷ lệ $6,3 \%$. Trong đó có 4 trường hợp can thiệp lại do rò nội mạch, 2 trường hợp rò nội mạch loại IA (33,3\%), 1 trường hợp rò nội mạch loại IB $(16,7 \%)$ và 1 trường hợp rò nội mạch loại II (16,7\%). Hai trường hợp còn lại là tắc ống ghép cần can thiệp xảy ra tương đối sớm sau phẫu thuật, 1 trường hợp xảy ra sau 1 tháng và 1 trường hợp xảy ra sau 4 tháng.

\section{Tỷ lệ tử vong}

Trong thời gian theo dõi trung hạn, có 20 bệnh nhân tử vong, chiếm tỷ lệ $21,1 \%$. Tỷ lệ tử vong chung (bao gồm tử vong trung hạn và chu phẫu) của chúng tôi là $22,1 \%$ (21 bệnh nhân). Trong các nguyên nhân tử vong, nhồi máu cơ tim cấp chiếm đa số với 5 trường hợp $(5,3 \%)$. Có 3 trường hợp tử vong do bệnh lý hô hấp là bệnh phổi tắc nghẽn mạn tính (COPD) và viêm phổi, chiếm tỷ lệ $3,2 \%$. Có 3 trường hợp tử vong tại nhà do già yếu $(3,2 \%), 2$ trường hợp tử vong do ung thư $(2,1 \%, 1$ do ung thư dạ dày và 1 do ung thư gan). Tử vong liên quan túi phình có 2 trường hợp $(2,1 \%), 1$ trường hợp rò ống ghép vào tá tràng và 1 trường hợp nhiễm trùng ống ghép. Tỷ lệ sống còn được miêu tả ở biểu đồ 1 và 2 


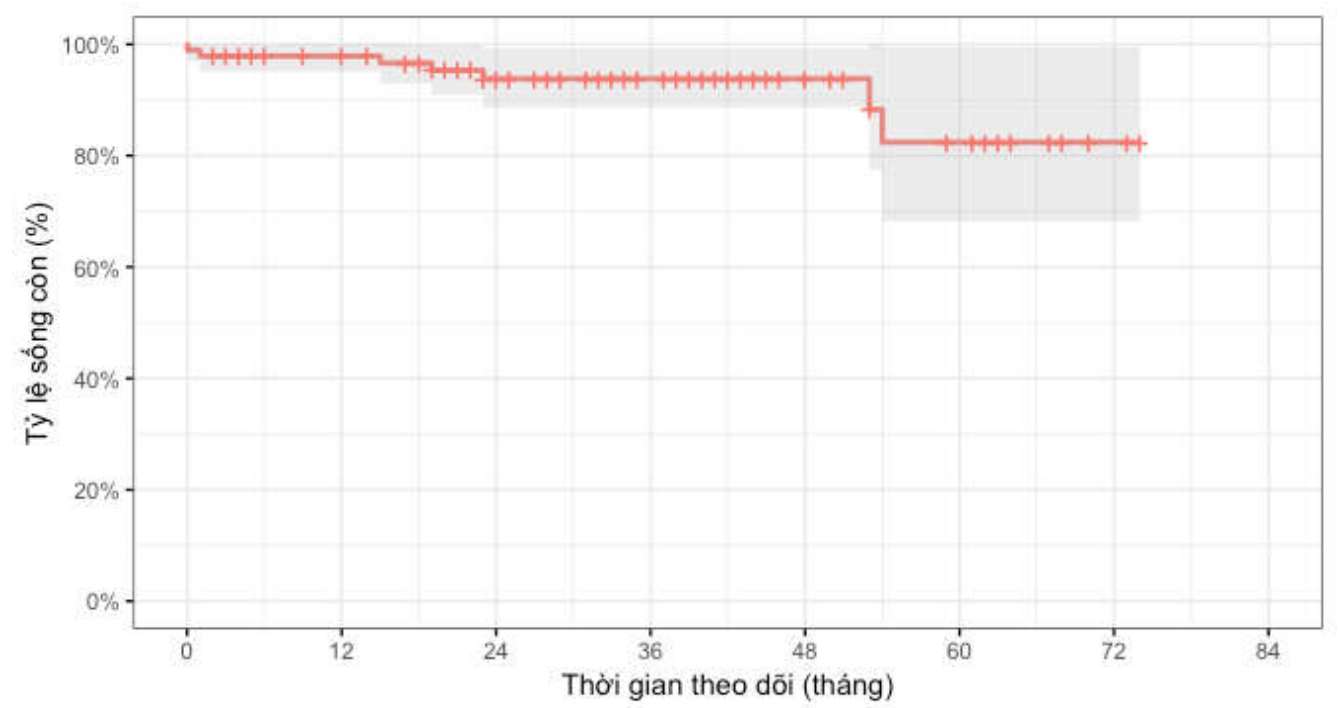

Số bệnh nhân có nguy cơ

\begin{tabular}{|c|c|c|c|c|c|c|c|}
\hline 95 & 85 & 61 & 36 & 21 & 13 & 4 & 0 \\
\hline 0 & 12 & 24 & 36 & 48 & 60 & 72 & 84 \\
\hline
\end{tabular}

Biều đồ 1: Biểu đồ Kaplan - Meier tử vong do mọi nguyên nhân

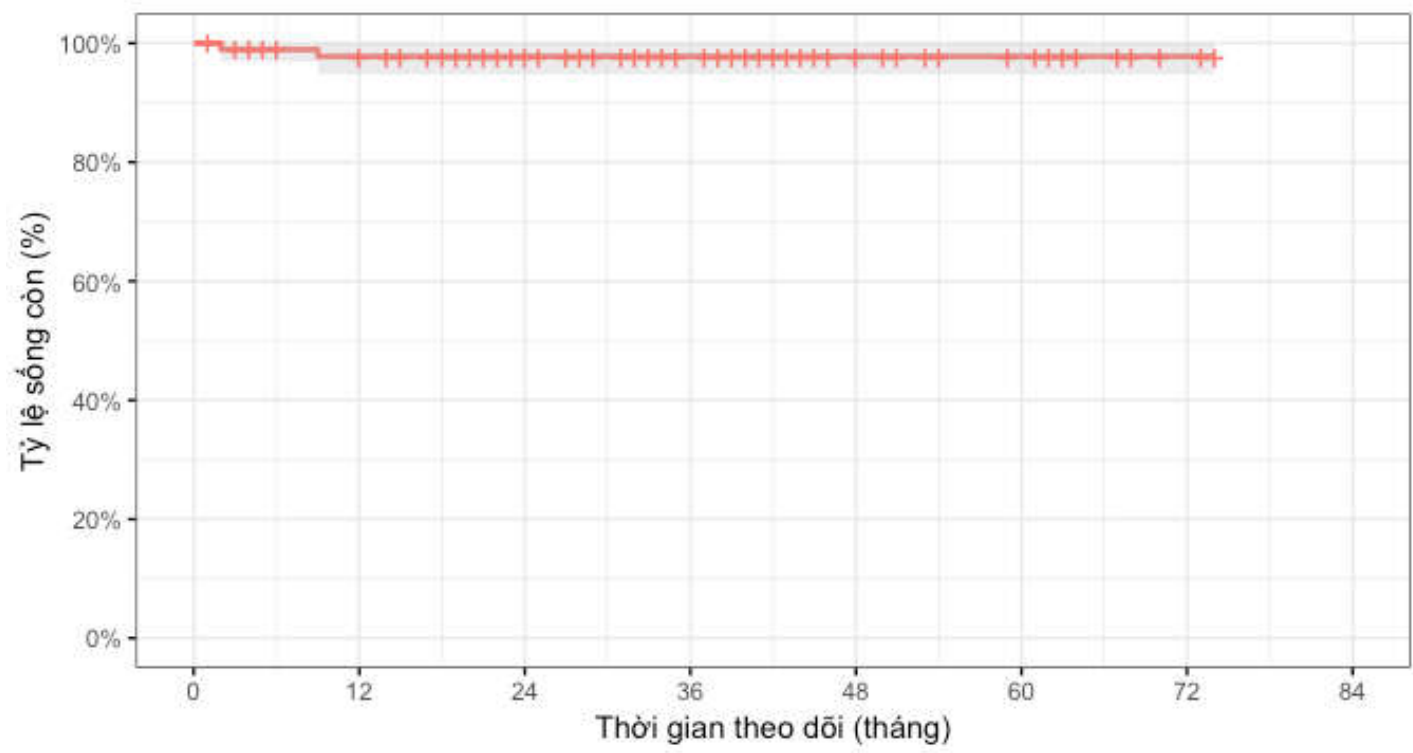

Số bệnh nhân có nguy cơ

\begin{tabular}{|ccccccccc|}
\hline 94 & 85 & 61 & 36 & 21 & 13 & 4 & 0 \\
\hline 0 & 12 & 24 & $\begin{array}{c}36 \\
12\end{array}$ & 48 & 60 & 72 & 84 \\
\hline
\end{tabular}

Biểu đồ 2: Biểu đồ Kaplan - Meier tử vong liên quan phình 


\section{BÀN LUẬN}

Các nghiên cứu trên thế giới đã chứng minh can thiệp nội mạch có kết quả ngắn hạn rất tốt so với phẫu thuật mở, can thiệp nội mạch động mạch chủ dường như đang mở ra một xu hướng mới để điều trị bệnh động mạch chủ, có khả năng thay thế phẫu thuật mở. Tuy vậy, cần phải đánh giá kết quả trung hạn cũng như lâu dài để có cái nhìn toàn diện hơn về phương pháp này.

Theo nghiên cứu của Behrendt và cộng sự [7], ưu thế về tỷ lệ tử vong và biến chứng của can thiệp nội mạch động mạch chủ so với phẫu thuật hở tồn tại đến khoảng 1,5 năm sau phẫu thuật. Sau thời gian này, tỷ lệ tử vong của hai nhóm là không có sự khác biệt có ý nghĩa thống kê ( $p=$ 0,708 ). Các yếu tố có liên quan đến tử vong trung hạn bao gồm: Sốc giảm thể tích, thiếu máu ruột, suy thận giai đoạn cuối, ngưng tim, tai biến mạch máu não, rung và cuồng nhĩ. Tương tự, tác giả Powell và cộng sự [6] sau khi thực hiện nghiên cứu gộp cũng nhận thấy không có sự khác biệt có ý nghĩa thống kê về tỷ lệ tử vong sau thời gian theo dõi trung và dài hạn giữa nhóm can thiệp nội mạch và nhóm phẫu thuật mở. Uu thế về tỷ lệ tử vong và biến chứng sớm của can thiệp nội mạch dừng lại sau 6 tháng. Sau 5 năm, tỷ lệ tử vong ước đoán là 73,6\% ở cả hai nhóm, $p=0,236$.

Trong nghiên cứu của chúng tôi, với thời gian theo dõi trung bình là 33 tháng, tỷ lệ tử vong trung hạn là $21,1 \%$. Trong đó có 2 trường hợp tử vong liên quan đến túi phình và 18 bệnh nhân tử vong không liên quan túi phình, trong đó nhồi máu cơ tim cấp chiếm đa số và 3 trường hợp do bệnh phổi tắc nghẽn mạn tính. Như vậy, tỷ lệ tử vong trung hạn của chúng tôi khá tương đồng với các tác giả ở trên, và cho thấy tử vong trung hạn của nhóm bệnh nhân can thiệp nội mạch động mạch chủ bụng tương đối cao.
Theo nghiên cứu của chúng tôi, tử vong trung hạn thường ít liên quan túi phình mà liên quan đến các bệnh lý nội khoa nhiều hơn, đặc biệt là các bệnh lý liên quan tim mạch và hô hấp. Vì vậy, bên cạnh việc theo dõi về can thiệp nội mạch, chúng tôi cho rằng nên phối hợp với các bác sĩ nội khoa tiếp tục tầm soát và theo dõi các nguy cơ tim mạch cũng như hô hấp để giảm thiểu tử vong trung hạn và dài hạn do các nguyên nhân này.

Bên cạnh tử vong trung hạn, biến chứng rò nội mạch, di lệch ống ghép và tỷ lệ can thiệp lại trong thời gian theo dõi cũng là một trong những nhược điểm của can thiệp nội mạch động mạch chủ. Đa số các can thiệp này đều liên quan đến túi phình. Trong khi đó, tỷ lệ can thiệp lại của phẫu thuật mở ít hơn và đa số liên quan đến các biến chứng của mở bụng.

Theo Powell và cộng sự [6], trong cả 4 thử nghiệm lâm sàng có nhóm chứng được theo dõi dài hạn và được xem xét trong nghiên cứu gộp của tác giả, tỷ lệ can thiệp lại chung của nhóm can thiệp nội mạch cao hơn phẫu thuật mở trong tất cả các thử nghiệm lâm sàng được xem xét. Trong nghiên cứu của chúng tôi, tỷ lệ can thiệp lại sau 33 tháng theo dõi trung bình là 6,3\% (6 bệnh nhân), tuy vậy, vẫn có hai bệnh nhân rò nội mạch type $\mathrm{IB}$ nhưng từ chối can thiệp lại. Vì vậy, nếu tính tỷ lệ cần can thiệp lại lý thuyết thì cần tính cả hai bệnh nhân này vào. Khi đó tỷ lệ can thiệp lại lý thuyết của chúng tôi tăng lên đến $8,4 \%$. Trong 8 trường hợp cần can thiệp lại, có 6 trường hợp liên quan đến túi phình (75\%), trong đó có 2 trường hợp rò nội mạch loại IA, 3 trường hợp rò nội mạch loại IB và 1 trường hợp rò nội mạch loại II, 2 bệnh nhân còn lại được can thiệp lại vì tắc ống ghép chậu một bên. Như vậy, tỷ lệ can thiệp lại của 
chúng tôi tương đối thấp hơn các tác giả trên. Lý giải điều này, chúng tôi cho rằng do thời gian theo dõi của chúng tôi ngắn hơn so với các nghiên cứu lớn, cũng như số lượng thấp hơn, vì vậy có thể tỷ lệ can thiệp lại trong thời gian dài hơn sẽ tăng lên gần tương đồng với các tác giả trên.

\section{KẾT LUẬN}

Qua kết quả nghiên cứu và bàn luận kết quả của các tác giả khác trên thế giới, chúng tôi nhận thấy rằng tỷ lệ tử vong trung hạn và tỷ lệ can thiệp lại trung hạn của can thiệp nội mạch động mạch chủ đều ở mức ngang bằng hoặc cao hơn so với phẫu thuật mở, nhất là ở thời gian theo dõi dài hơn 5 năm. Như vậy, can thiệp nội mạch động mạch chủ rất có lợi trên những bệnh nhân lớn tuổi, thời gian sống còn không dài, nguy cơ phẫu thuật cao. Tuy nhiên, ở những bệnh nhân trẻ tuổi hơn, ít nguy cơ phẫu thuật thì phẫu thuật hở vẫn lợi ích hơn, đặc biệt là ở giai đoạn dài hạn. Vì vậy, khi đánh giá bệnh nhân phình động mạch chủ bụng dưới thận cần can thiệp, cần cân nhắc kỹ lưỡng các yếu tố nguy cơ, thời gian sống còn, lợi ích ngắn hạn và lợi ích lâu dài, đồng thời bác sĩ phẫu thuật có thể cung cấp được cả hai lựa chọn: can thiệp nội mạch và phẫu thuật hở để có thể đem lại lựa chọn tốt nhất cho người bệnh, giúp cải thiện tỷ lệ tử vong, biến chứng và can thiệp lại trong giai đoạn ngắn hạn và dài hạn.

\section{TÀI LIỆU THAM KHẢO}

1. England A, Mc Williams R: Endovascular aortic aneurysm repair (EVAR). Ulster Med J 2013, 82(1):3-10.

2. Propper BW, Abularrage CJ: Long-term safety and efficacy of endovascular abdominal aortic aneurysm repair. Vasc Health Risk Manag 2013, 9:135-141.

3. Becquemin JP, Pillet JC, Lescalie F, Sapoval M, Goueffic Y, Lermusiaux P, Steinmetz E, Marzelle J, trialists ACE: A randomized ontrolled trial of endovascular aneurysm repair versus open surgery for abdominal aortic aneurysms in low- to moderate-risk patients. J Vasc Surg 2011, 53(5):1167-1173 e1161.

4. Trần Quyết Tiến, Phạm Minh Ánh: Can thiệp đặt ống ghép nội mạch điều trị phình động mạch chủ bụng tại khoa phẫu thuật mạch máu, Bệnh viện Chợ Rẫy. Tạp chí Y Dược học Quân sự số 2- 2014 2014, 157 - 164.

5. Nguyễn Văn Quảng, Phạm Minh Ánh, Trần Quyết Tiến: Kết quả điều trị 52 trường hợp phình động mạch chủ bụng dưới thận bằng can thiệp nội mạch tại bệnh viện Chợ Rẫy. Y học TP Hồ Chí Minh 2017, 21(2):187-194.

6. Powell JT, Sweeting MJ, Ulug P, Blankensteijn JD, Lederle FA, Becquemin JP, Greenhalgh RM, Evar DO, Trialists ACE: Metaanalysis of individual-patient data from EVAR-1, DREAM, OVER and ACE trials comparing outcomes of endovascular or open repair for abdominal aortic aneurysm over 5 years. $\mathrm{Br} \mathrm{J}$ Surg 2017, 104(3):166-178.

7. Behrendt CA, Sedrakyan A, Riess HC, Heidemann F, Kolbel T, Petersen J, Debus ES: Short-term and long-term results of endovascular and open repair of abdominal aortic aneurysms in Germany. J Vasc Surg 2017, 66(6):1704-1711 e1703. 